\title{
AOR
}

Selected Papers of \#AolR2021:

The 22nd Annual Conference of the

Association of Internet Researchers

Virtual Event / 13-16 Oct 2021

\section{QUARANTINE VLOGS: DIGITAL AFFECTIVE LABOR AND SELF- GOVERNANCE DURING COVID-19}

\author{
Alkım Yalın \\ University of Massachusetts-Amherst
}

Scholars indicate that vlogs are based on confessional narratives of intimate events (Berryman \& Kavka, 2018), characterized by "controlled presentations" (Griffith \& Papacharissi, 2010) of the self, and a "calibrated amateurism" (Abidin, 2017) through which vloggers try to convey a sense of intimacy, relatability and "perceived interconnectedness" (Abidin, 2015) to their viewers. Like previous genres of diaries and blogs, vlogs function as Foucauldian "technologies of the self" through which vloggers turn their everyday life into a self-reflexive project and align with the neoliberal discourse of productivity (Siles, 2012; Ibrahim, 2020). Thus, compared to former genres, construction of the "authentic self" in vlogs is not the primary goal but a necessary tool to form intimacy with the audiences. For women content creators, this complex selfrepresentation framework implies gendered affective labor, through which they try to brand themselves in accordance with the post-feminist discourse of entrepreneurial femininity by showing "the ideal of having it all" (Duffy \& Hund, 2015) and carrying out "visibility labor" to survive in a highly competitive attention economy (Abidin, 2016).

COVID-19 changed what people considered appropriate to share on social media platforms as the realities of the pandemic shifted users' perception of aspirational content negatively and led them to seek more authenticity (Molla, 2021). In response to this shift, influencers adapted their content to the pandemic moment and the audience expectations. Shortly after many countries started to take precautions against the spread of the COVID-19, such as stay home orders, a new subgenre of the vlog, namely the "quarantine vlog" started to appear on YouTube.

This research explores how did the COVID-19 effect the cultural production of influencers - specifically, the affective labor carried out by women content creators - by examining the recent genre of "quarantine vlog." Quarantine vlogs carry the quintessential characteristics of the vlog genre. However, they differ from other vlogs,

Suggested Citation (APA): Yalın, A. (2021, October). Quarantine Vlogs: Digital Affective Labor and SelfGovernance During Covid-19. Paper presented at AolR 2021: The 22nd Annual Conference of the Association of Internet Researchers. Virtual Event: AolR. Retrieved from http://spir.aoir.org. 
and I explain this dissimilarity as a tension between influencers' struggle to form intimacy with the viewers - which can have a soothing effect in a moment of a crisis and the use of vlogs as a neoliberal device to preserve their aspirational image.

In this preliminary analysis, I draw upon "grounded theory approach" (Charmaz, 2006). In parallel to my ongoing research on influencer cultures, I realized the emergence of quarantine vlogs in March 2020. Later, with a combination of top search results and purposive sampling, I transcribed and analyzed 9 videos filmed by women influencers along with 250 user comments. I transcribed the videos by using YouTube's own transcription tool and coded them along with the comments by using qualitative data analysis software NVivo. During this coding process, which took place in concurrence with the data collection process, I used the line-by-line coding method as proposed by Charmaz (2006) to analyze the emerging themes and patterns both in the videos and comments. A limitation to this study is its focus on content creators based in North America. However, comments demonstrate that viewers are located in different parts of the world.

Quarantine vlogs demonstrate that influencers are not able to perform the "having-it-all" (Duffy \& Hund, 2015) personae in their videos without first engaging with the mental stress, anxiety, confusion, and loneliness brought by COVID-19 or apologizing for their relative privilege and demonstrating sympathy towards their followers who are in hardship. In this sense, by using "negative affect" (Berryman \& Kavka, 2018) in their vlogs, content creators perform care, which is both necessary to build intimacy with the viewers and stay visible and relevant in a demanding attention economy as a woman. Some content creators can also choose to frame their decision to film a quarantine vlog as a way to provide distraction for their viewers or to "check in" with them. The fact that many commenters reporting to find quarantine vlogs soothing, while they define the community mainly as providing a "feminine" and "safe" space confirms the gendered affective labor carried out by the content creators.

In quarantine vlogs, content creators' affective labor consists of a delicate selfgoverning strategy. Creators engage in a 'dialogue with time' (Giddens, 1991), which consists of re-designing the past and the future through nostalgic imagery and the ideal of progress. This revised performance helps them to extend their established aspirational personae to the pandemic conditions by 1) conjuring up memories to reimagine a pleasurable past that deserves nostalgic longing, 2) acknowledging the anxieties and material difficulties tied to pandemic but addressing the current moment as an opportunity to grow as an individual or to be productive, and finally, 3) reframing the pandemic experience as the precursor of a better future to come. The placement of the self in this reflexive and temporal project through the discourses of productivity and self-growth constructs the quarantine vlog as a Foucauldian technology of the self. At the same time, this self-governance manages the relationship with the audiences by presenting a relatable yet "aspirational" (Duffy, 2017) persona that is tailored according to the pandemic moment.

To conclude, quarantine vlogs and the comments they received are strong indicators that even during a global health crisis, to stay relevant and visible online, women content creators need to carry out affective labor by performing care and proving their 
resilience in staying productive. It is also remarkable how the configuration of time that is specific to quarantine vlogs, i.e. the reproduction of nostalgia and the reframing of the pandemic as an opportunity for self-improvement, does not easily drift apart from the neoliberal ideal of productivity however users' everyday life experiences may have shifted during the pandemic.

\section{References}

Abidin, C. (2015). "Communicative $<3$ Intimacies: Influencers and perceived interconnectedness." Ada: A Journal of Gender, New Media, \& Technology 8. Accessed August 5, 2016 from http://adanewmedia. org/2015/11/issue8-abidin/

Abidin, C. (2016). Visibility labour: Engaging with Influencers' fashion brands and \#OOTD advertorial campaigns on Instagram. Media International Australia, 161(1), 86100. https://doi.org/10.1177/1329878X16665177

Abidin, C. (2017). \# familygoals: Family influencers, calibrated amateurism, and justifying young digital labor. Social Media+ Society, 3(2), 2056305117707191.

Berryman, R., \& Kavka, M. (2018). Crying on YouTube: Vlogs, self-exposure and the productivity of negative affect. Convergence, 24(1), 85-98.

https://doi.org/10.1177/1354856517736981

Charmaz, K. (2006). Constructing grounded theory: A practical guide through qualitative analysis. Sage Publications.

Duffy, B. E., \& Hund, E. (2015). "Having it All" on Social Media: Entrepreneurial Femininity and Self-Branding Among Fashion Bloggers. Social Media + Society. https://doi.org/10.1177/2056305115604337

Duffy, B. E. (2017). (Not) getting paid to do what you love: Gender, social media, and aspirational work. Yale University Press.

Giddens, A. (1991). Modernity and self-identity: Self and society in the late modern age. Stanford University Press.

Ibrahim, Y. (2020). Accounting the 'self': From diarization to life vlogs. Convergence. https://doi.org/10.1177/1354856520947618

Molla, R. (2021). Posting less, posting more, and tired of it all: How the pandemic has changed social media. Vox. https://www.vox.com/recode/22295131/social-media-usepandemic-covid-19-instagram-tiktok

Raun, T. (2018). Capitalizing intimacy: New subcultural forms of micro-celebrity strategies and affective labour on YouTube. Convergence, 24(1), 99-113.

https://doi.org/10.1177/1354856517736983 
Siles, I. (2012). The rise of blogging: Articulation as a dynamic of technological stabilization. New Media \& Society, 14(5), 781-797.

https://doi.org/10.1177/1461444811425222 